\title{
Evaluate the Effects of Various Surface Roughness on the Tribological Characteristics under Dry and Lubricated Conditions for Al-Si Alloy
}

\author{
Riyadh A. Al-Samarai ${ }^{*}$, Haftirman ${ }^{1}$, Khairel Rafezi Ahmad ${ }^{2}$, Y. Al-Douri ${ }^{3}$ \\ ${ }^{1}$ School of Mechatronic Engineering, University Malaysia Perlis, Ulu Pau, Malaysia; ${ }^{2}$ School of Materials Engineering, University \\ Malaysia Perlis, Arau, Malaysia; ${ }^{3}$ Institute of Nano Electronic Engineering, University Malaysia Perlis, Kangar, Malaysia. \\ Email: Al_badri70@yahoo.com
}

Received April $1^{\text {st }}, 2012$; revised May $3^{\text {rd }}, 2012$; accepted May $25^{\text {th }}, 2012$

\begin{abstract}
The effect of surface roughness average of hypereutectic aluminum silicon alloys (with $16 \mathrm{wt} \% \mathrm{Si}$ ) on the friction and wear was investigated. Various surface roughness average (Ra) of different degrees was verified as well as three different loads 10,20 and $30 \mathrm{~N}$, speeds 200, 300 and $400 \mathrm{rpm}$ and relative humidity $77 \%$. Different surface preparation techniques are resulted in different Ra values from $(6,8$ and 12) $\pm 0.05 \mu \mathrm{m}$. The contacts were dried sliding and lubricated regime at 2.5 centimeters per second. Surfaces were analyzed with scanning electron microscopy and X-ray dispersive analyses. It was noted that the weighted and volumetric wear rate decreases as degree of roughness decreases, as well as coefficient of friction is considered as a function of the stability state. Wear rate is decreased and the transition stress from high to low wear is increased with increasing surface roughness average. There was a correlation between friction coefficient and hardness.
\end{abstract}

Keywords: Aluminum-Silicon Alloy; Boundary Lubrication; Casting; Surface Roughness; Adhesive Wear

\section{Introduction}

Aluminum-silicon casting alloys are widely used in internal-combustion engines as cylinder heads, cylinder blocks, and pistons. Demands are increasing on improveing the effectiveness of mechanical parts and reduce friction to increase the energy density [1]. Surface roughness is a major problem during the production process and greatly affects the quality of the product [2]. One of the factors that affect the age of surfaces is the roughness which is inherent to the process of friction, also high roughness means increasing the proportion of friction, adhesion and thereby increases the rate of shear connections between surfaces [3], which leads to increased wear and loss of parts and processors that used in lubricants. To understand the roughness [4] as well as coefficient of friction [5], it is better to know the sliding affects the surface roughness through the contacts between surfaces and leads to deformation causing an economic damage $[6,7]$. The installation and texture surface could increase the load hydrodynamic as well as the film thickness and thus increase the surfaces life to reduce the cost of the speed process of wear $[8,9]$.

Menezes et al. [10] have studied the effects of rough-

*Corresponding author. ness parameters on the friction of aluminum alloy under conditions of lubrication. They concluded that the coefficient of friction and wear are depending on the roughness. $\mathrm{Ku}$ et al. [11] have observed the surface finishing and termination of many applications in mechanical wheels and found the necessity to control the termination surface well to reduce the effect of surface roughness and friction within operations of sliding. It is important to know the quality of the surfaces roughness that requires a process of coating and treatment to protect it of damage [12]. Karpenko and Akay [13] have been studied the effect of roughness between two surfaces using an algorithm to calculate the coefficient of friction between them. They concluded that there is a flexible deformation and shearing resistance depend on external loads, mechanical properties and topography surfaces to give approximate limits of influence. To increase the process of wear and damaged surfaces, we must take into consideration the mechanical properties affect the process [14]. Wieleba [15] had studied roughness and stiffness of composite materials against steel and showed its effect on the friction and wear. Chowdhury and Maksud [16] have searched the effect of humidity on surface roughness and found that the friction is very high at low roughness and tends to be increased at high horizontal vibration. $\mathrm{Al}-\mathrm{Si}$ 
alloys have been studied interestingly, but did not take into consideration the roughness study. Xing et al. [17] have prepared the hypereutectic $\mathrm{Al}-17.5 \mathrm{Si}$ (wt pct) and $\mathrm{Al}-25 \mathrm{Si}$ (wt pct) alloys with various content of rare earth Er by conventional casting technique. They investigated the effect of Er on the microstructure and properties of hypereutectic Al-Si alloys using optical microscopy, scanning electron microscopy (SEM) as well as friction and wear tests and noticed an improvement of the antiwear properties and the friction coefficient of the hypereutectic Al-Si alloys. Gupt and Ling [18] have synthesized three aluminum-silicon alloys containing 7, 10 and $19 \mathrm{wt} \%$ silicon using a novel technique commonly known as disintegrated melt deposition technique. Their results revealed that a yield of at least $80 \%$ can be achieved after defacing the shrinkage cavity from the as-processed ingots and demonstrated an increase in matrix microhardness, while $0.2 \%$ yield stress decreases in ductility with an increase in silicon content. They investigated the effect of extrusion on Al-19Si alloy and showed a correlation of microstructural characterization and mechanical properties of aluminum-silicon alloys with the amount of silicon and secondary processing technique. Finally, Li et al. [19] have prepared and fabricated hypereutectic Al-Si alloys by hot extrusion. They investigated the tensile fracture mechanisms using SEM and proved an improvement of wear resistance due to silicon particles refining.

In this work, to best of our knowledge, investigation of roughness on the wear rate with sliding distance and velocity of Al-Si casting alloy, on the volumetric wear rate and friction coefficient with normal load is not available in the literature. It was attempted to bridge the gap between the damages resulting from the sliding surfaces and surface roughness effect on the friction and wear to provide an approach for evaluation the surface finishing operations. All of these are divided into the followings: Section 2 displays the experimental process, while results and discussion are given in Section 3, followed by conclusions.

\section{Experimental Procedure}

The wear studies were performed for the measurements as shown in Figure 1. The load of the pin against the disc was $10,20,30 \mathrm{~N}$ and the angular speed of the disc was $200,300,400 \mathrm{rpm}$ equals to $1.32,1.88,5.3 \mathrm{~m} / \mathrm{s}$. For Al-16Si casting alloy; $R_{\mathrm{a}}=(4,6,8) \pm 0.05 \mu \mathrm{m}, \mathrm{Hv}=$ $112.65 \pm 12 \mathrm{~kg} / \mathrm{mm}^{2}$ on disc, made of AISI 1045 steel, and $R_{\mathrm{a}}=0.15 \pm 0.05 \mu \mathrm{m}, \mathrm{Hv}=312 \pm 20 \mathrm{~kg} / \mathrm{mm}^{2}$ were used for testing. Firstly, and before testing, aluminum silicon disc was cleaned and dried using cotton and acetone as the weight of the samples was measured using a digital balance and recording the values before and after the test for each test.

Chemical analysis was conducted for the aluminumsilicon casting alloy, also density, hardness and tensile strength are studied due to its widely used in industry, particularly in pistons as well as the cylinders. The obtained chemical analysis is given in the Table 1. The testing of mechanical properties including hardness is given in Table 2.
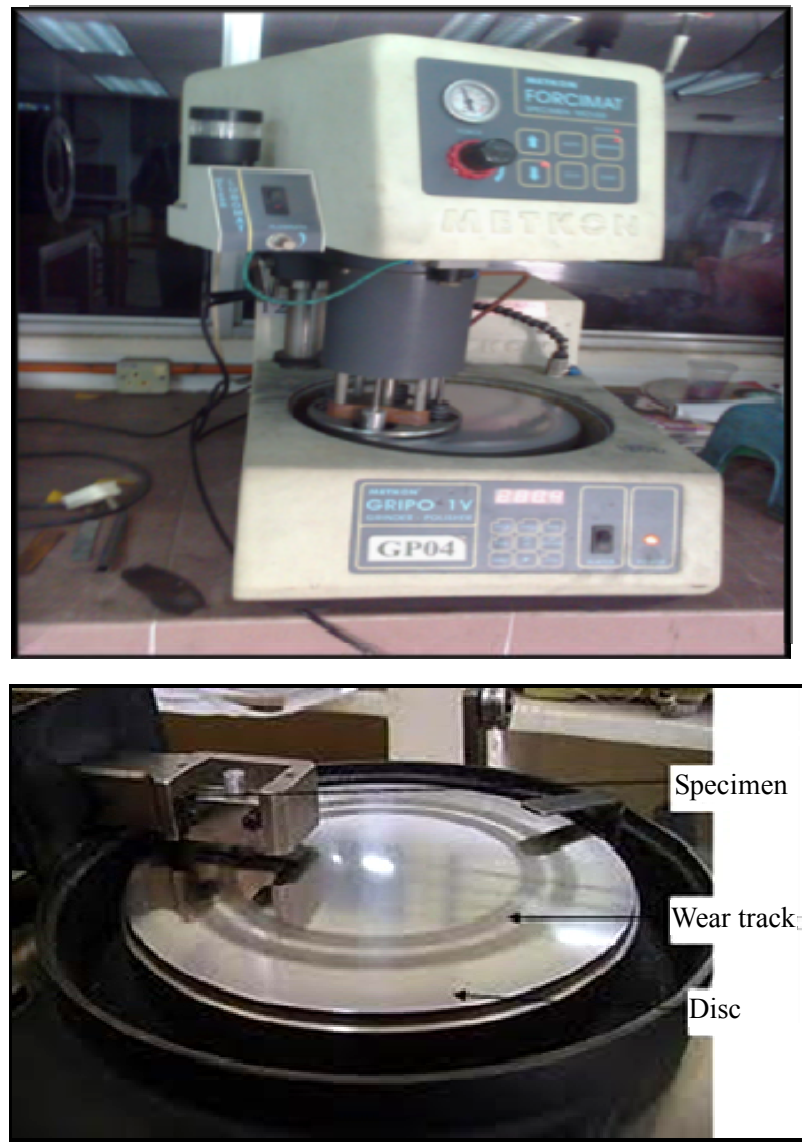

Figure 1. Pin-on-disc wear testing machine.

Table 1. Compositional analysis of Al-Si casting alloy.

\begin{tabular}{ccccccccc}
\hline $\mathrm{Si}$ & $\mathrm{Mg}$ & $\mathrm{Cu}$ & $\mathrm{Fe}$ & $\mathrm{Ni}$ & $\mathrm{Mn}$ & $\mathrm{Sn}$ & $\mathrm{Pb}$ & $\mathrm{Zn}$ \\
\hline 16.69 & 1.176 & 1.304 & 1.130 & 1.224 & 0.024 & 0.012 & 0.026 & 0.012
\end{tabular}

Table 2. Investigated hardness, density and tensile strength of Al-Si casting alloy.

\begin{tabular}{cc}
\hline Hardness & $112.65 \mathrm{VHN}$ \\
\hline Density & $2.72 \mathrm{gm} / \mathrm{cc}$ \\
Tensile strength & $250 \mathrm{MPa}$ \\
\hline
\end{tabular}


The microscopic structure and the composition of microscopic samples are examined and shown in Figure 2. It is shown that $\mathrm{Si}$ particles are distributed uniformly, while the $\mathrm{Si}$ seems a bulk. The scanning electron microscopy (SEM) images give greater magnification and better depth. SEM is a specialized method using a variable-pressure sample chamber, This technique allows direct evaluation of samples that are nonconductive or vacuum sensitive.

Aluminum-silicon casting alloy was cleaned then starting an actual test of wear process and the hard substance acetone with cotton and dry well was registered height and weight of samples accurately to provide a very precise and digital recording of all data using a stopwatch to set a time slip and post-test. And continuously measuring the friction force. At preselected times the pin wear was determined by measuring the wear-scar diameter. Friction force was recorded during the wear tests. Specimens were ultrasonically cleaned in acetone for $5 \mathrm{~min}$ before and after wear tests. More than three wear tests were repeated under the same lubrication condition. The wear tracks were observed by SEM. Surface roughness was also measured by a stylus surface analyzer, with the effective measure length $0.25 \mathrm{~mm}$ and the cutoff length, $0.05 \mathrm{~mm}$. The work hardening of con- tact surfaces due to the friction shear was identified and determined by micro-Vickers indentation test.
Wear rate $\left(W_{R}\right)$ was estimated by measuring the mass loss $(\Delta W)$ in the specimen after each test. Cares have been taken after each test to avoid entrapment of wear debris in the specimen. It is calculated that $\Delta W$ to sliding distance (S.D) using:

$$
W_{R}=\Delta W / S . D
$$

The volumetric wear rate $\left(W_{V}\right)$ of the composite is related to density $(\rho)$ and the abrading time $(t)$, using:

$$
W_{V}=\Delta W / \rho t
$$

Specific wear rate $\left(W_{s}\right)$ is employed. This is defined as the volume loss of the composite per unit sliding distance and per unit applied normal load. Often the inverse of specific wear rate expresses in terms of the volumetric wear rate as:

$$
W_{S}=W_{V} / S \cdot D F n
$$

The friction force was measured for each pass and then averaged over the total number of passes for each wear test. The average value of friction coefficient $(\mu)$ of composite was calculated from:

$$
\mu=F f / F n
$$

where $F f$ is the average friction force and $F n$ is the applied load with an assumption that the temperature is constant at $33^{\circ} \mathrm{C}$.
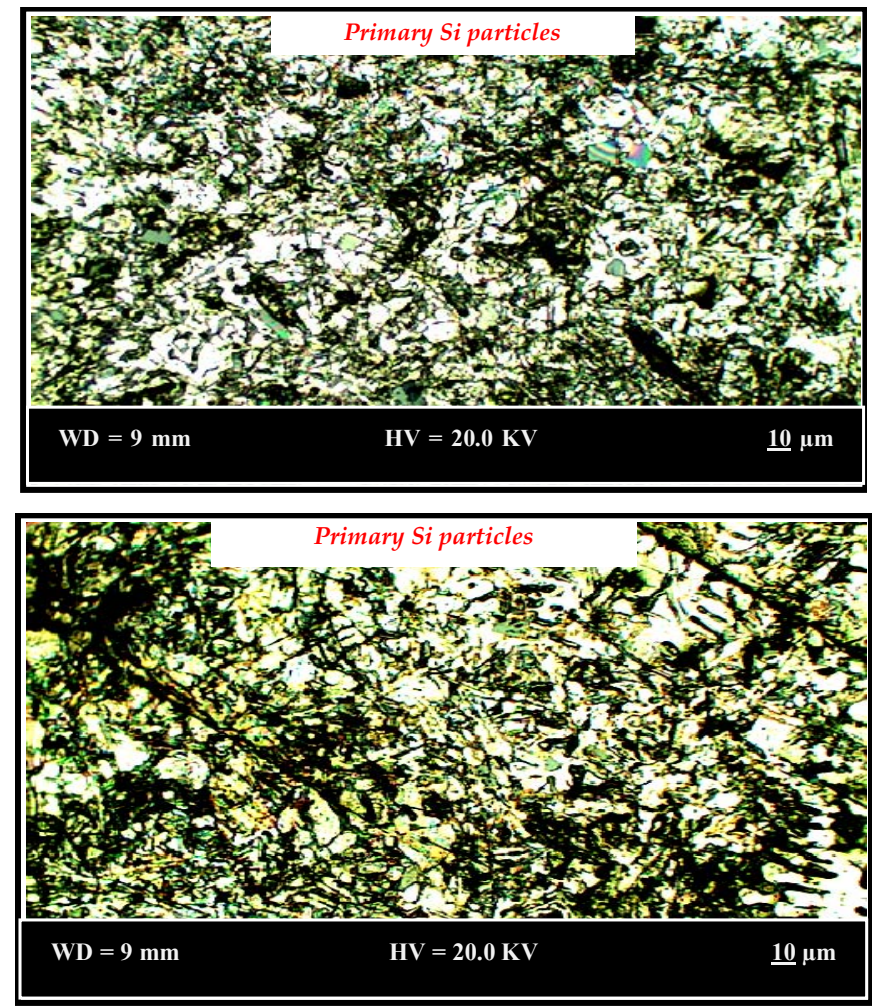

Figure 2. The SEM images of microscopic structures of Al-Si casting alloy. 


\section{Results and Discussion}

The wear rate of Al-Si alloys in lubricated contacts has been studied and compared with dry sliding. Based on the obtained results, it is plotted for different surface roughness average $(\mathrm{Ra})=6,8$ and $12 \mu \mathrm{m}$ under conditions of the sliding speed equals to $1.32,1.885$ and 3 $\mathrm{m} / \mathrm{sec}$ within the range of different loads; 10, 20 and 30 $\mathrm{N}$ as shown in Figure 3. It is noted for $10 \mathrm{~N}, \mathrm{Ra}=12 \mu \mathrm{m}$ gives the highest percentage of wear rate equals to $0.16835 \times 10^{-6}(\mathrm{~N} / \mathrm{m})$, while for $R \mathrm{a}=8$ and $6 \mu \mathrm{m}$ give $0.14731 \times 10^{-6}(\mathrm{~N} / \mathrm{m})$ and $0.1473 \times 10^{-6}(\mathrm{~N} / \mathrm{m})$, respecttively, which are equal to the first hour of testing then goes down slightly. The sliding occurs in very small areas at the peaks, rupture or break these summits becomes more sliding accompanied by a rise in temperature while increasing the load causes increasing the friction rate, which in turn increases the destruction, surface wear reduces the contact area and break the oxide layer causes an adhesion. The wear of Al-Si alloys in lubricated contacts, as compared with the wear of dry sliding, has some interesting features. The alloys progressed from a highwear-rate region to a low-wear-rate region. It was observed in Figures 3(a) and (b) that the wear rate increases as load increases.

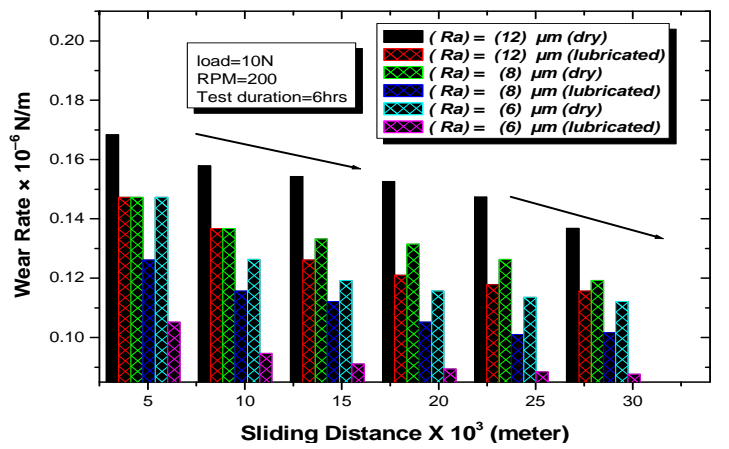

(a)

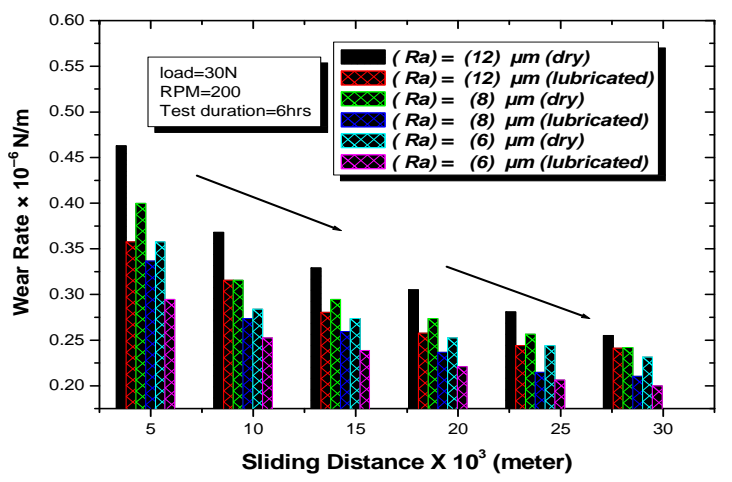

(b)

Figure 3. Variation of surface roughness $R_{\mathrm{a}}=6,8$ and $12 \pm$ $0.05 \mu \mathrm{m}$ and wear rate with sliding distance at $200 \mathrm{rpm}$, at (a) load of $10 \mathrm{~N}$; (b) load of $30 \mathrm{~N}$ under dry and lubricated conditions.
The highest roughness average means the highest wear rate and the correlation between wear rate and sliding distance is inversely. This is the force required to cut the interdependence between the bumps. Little wear rate is a qualitative increase of load at $10 \mathrm{~N}$ and showed the results of the surface at $R \mathrm{a}=12 \mu \mathrm{m}$ has amount of specific wear equals to $W S=5.619667 \times 10^{-13}\left(\mathrm{~m}^{3} / \mathrm{N}-\mathrm{m}\right)$, higher slightly than with $R \mathrm{a}=8 \& 6 \mu \mathrm{m}$ as shown in Figure 3 . These amounts are depending on the surface roughness as well as increasing the wear rate. The main reason for lacking wear resistance at the beginning of the test is attributed to the thin layer of material eroded between bumps of the disk surface, the sliding leads to hardness, low rate of wear and surface roughness while the variation of volumetric wear rate with normal load is directly as shown in Figure 4. The relationship at $200 \mathrm{rpm}$ is positively correlated linear and the volumetric wear value for $R \mathrm{a}=12 \mu \mathrm{m}$ equals to $W_{V}=7.41817 \times 10^{-12}\left(\mathrm{~m}^{3} / \mathrm{sec}\right)$ at the beginning of the test carrying $10 \mathrm{~N}$ and it increases with increasing load to 20 and $30 \mathrm{~N}$. Increasing of roughness can be noticed with increasing $W_{V}$ of different rpm values due to same reason of specific wear rate of lacking wear resistance of material thin layer eroded between bumps of the disk surface, while $W_{V}$ decreases as $R$ a decreases for the same rpm as cleared in Figure 4.
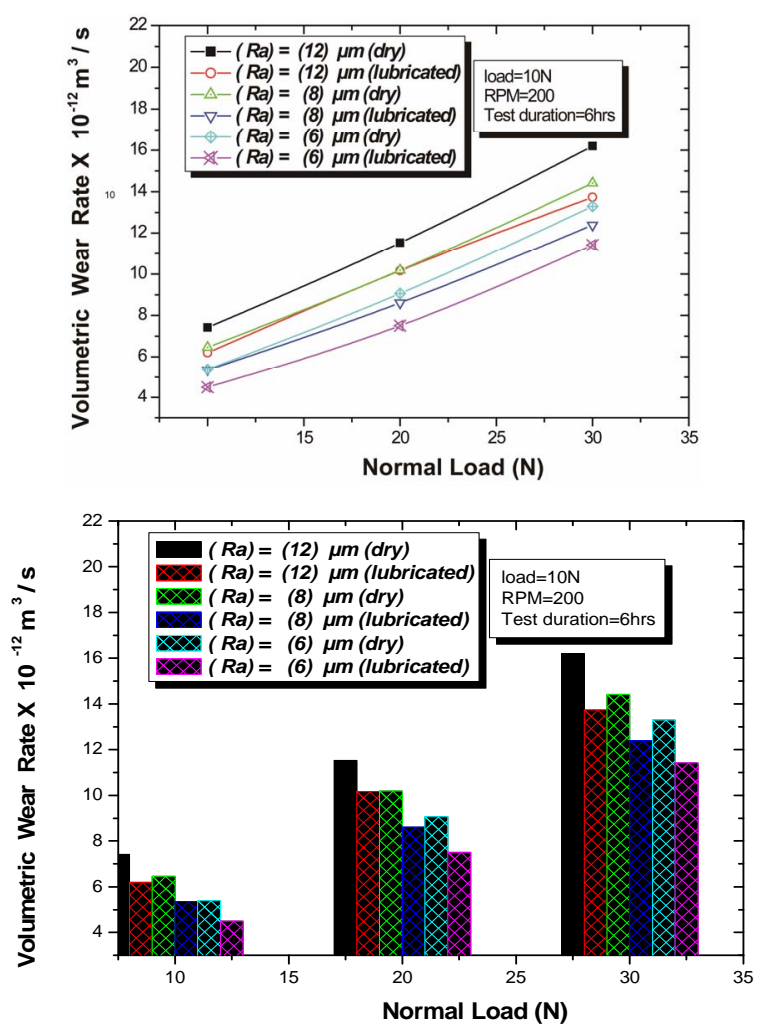

Figure 4. Variation of surface roughness $R_{\mathrm{a}}=6,8$ and $12 \pm$ $0.05 \mu \mathrm{m}$ and volumetric wear rate with normal load of $10 \mathrm{~N}$ at $200 \mathrm{rpm}$ under dry and lubricated conditions. 
We note that an increase of load to $30 \mathrm{~N}$ leads to decreasing of specific wear rate. Due to the period of rubbing, the initial broken layers of the surface become clean, increase the strength of the connections, increase the friction force due to the tillage effect between the surfaces, increase the temperature and the adhesion increases the deformation of the surface layers that lead to increasing loss of the metal. The correlation of specific wear rate with sliding velocity is inversely and shown in Figure 5.

The friction coefficient decreases as the load increases as shown in Figure 6 that leads to plastic flow in the sliding surfaces. Friction coefficient is a function of wear rate. Increasing of real area of contact causes an increasing of space connections and friction force, while increasing the surfaces temperature leads to gradually flattening the protrusions to obtain steady-state and higher speed of high temperature during the slide, which reduces the shear force, reduce the friction coefficient and roughness as a result of surface smoothness. The friction is an important factor of wear and is influenced by many factors including nature of sliding, load and type of surface-related as well as lubrication. The mechanism of wear adhesive is to draw roughness with high-precision of tripology behavior in addition to many affected factors at low friction coefficient with increasing load and sliding speed due to change in shear rate, which can affect the mechanical properties of materials. For the same velocity. In the Figure 7 we note a comparison between dry sliding and lubrication and the effect of wear larger surface during dry sliding, compared with lubrication sliding, the wear rate on the surface is increased as load increases influence wear behavior and can be examined.

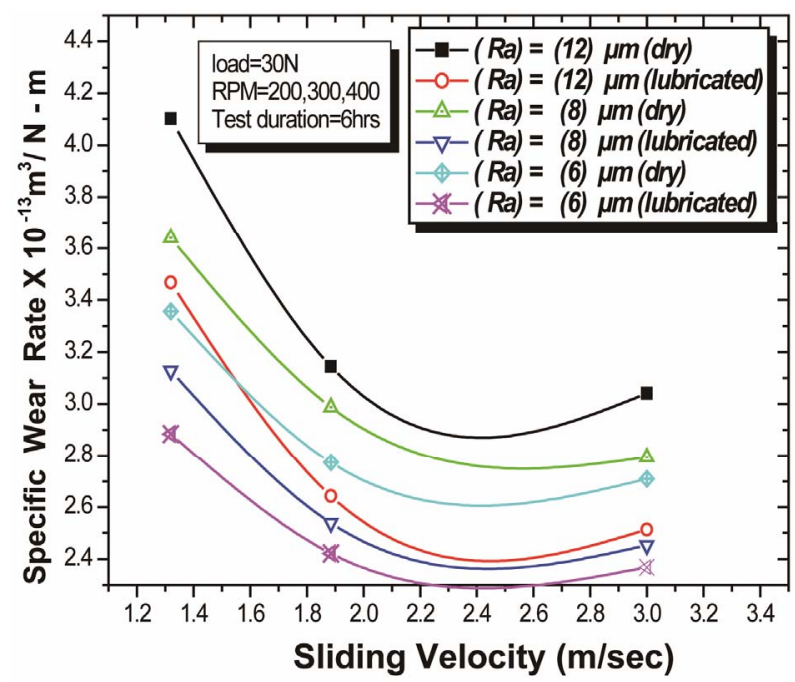

Figure 5. Variation of surface roughness $R a=6,8$ and $12 \pm$ $0.05 \mu \mathrm{m}$ and specific wear rate with sliding velocity of 200 , 300 and $400 \mathrm{rpm}$ at $30 \mathrm{~N}$ under dry and lubricated conditions.
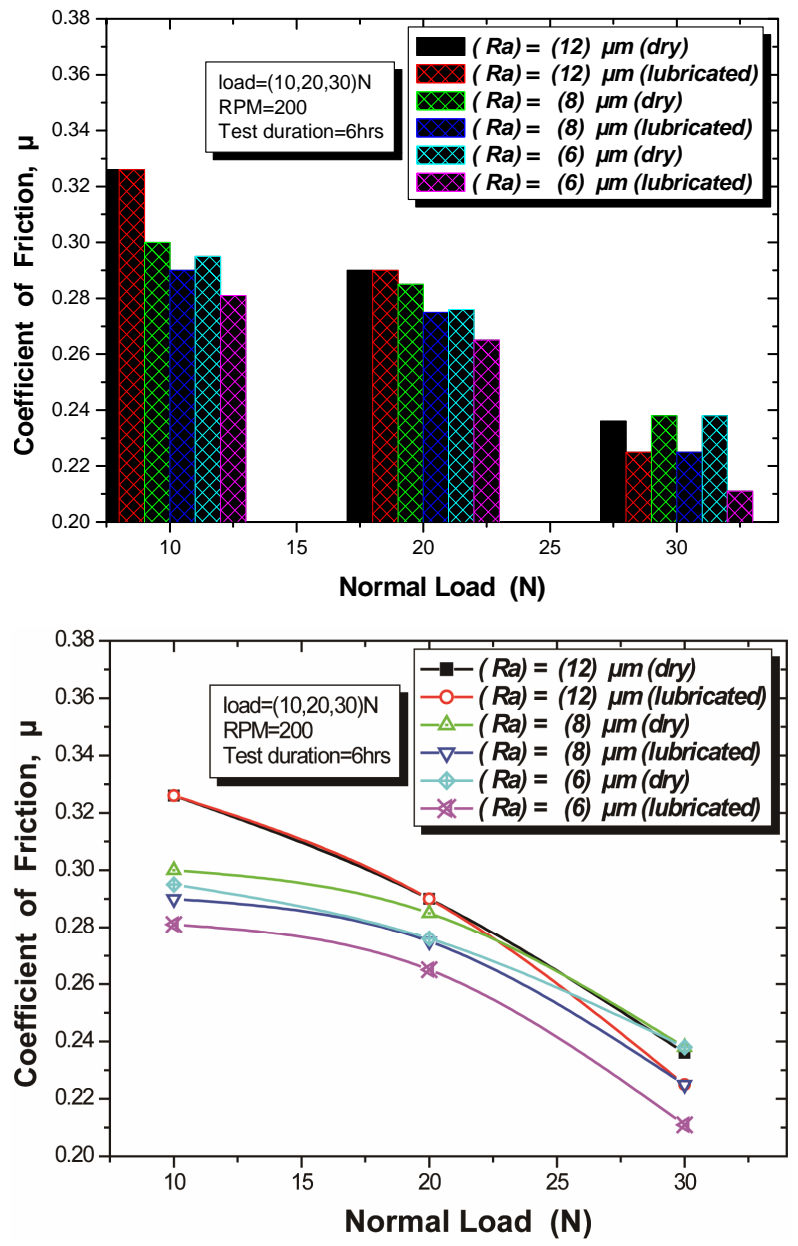

Figure 6. Variation of surface roughness $R_{\mathrm{a}}=6,8$ and $12 \pm$ $0.05 \mu \mathrm{m}$ and coefficient of friction with normal load of 200 rpm at 10, 20, $30 \mathrm{~N}$ under dry and lubricated conditions.

Chemical effects such as oxidative wear or lubricant interactions may composition (chemical property) in the sense that the scatter in the data was less. The same images of micrographs wear surface show increasing as load increases as in Figure 8. It is observed by performing similar experiments in an inert atmosphere. The wear rate correlated better with hardness (mechanical property).

\section{Conclusions}

In summary, using the investigated results, the following conclusions can be obtained:

- Wear rate and the transition stress in going from high to low wear correlate with the surface roughness average $(R a)$;

- The alloys go from a high- to a low-wear-rate regime with-sliding distance;

- There seems to be little correlation between friction coefficient and the wear rate, silicon content; 

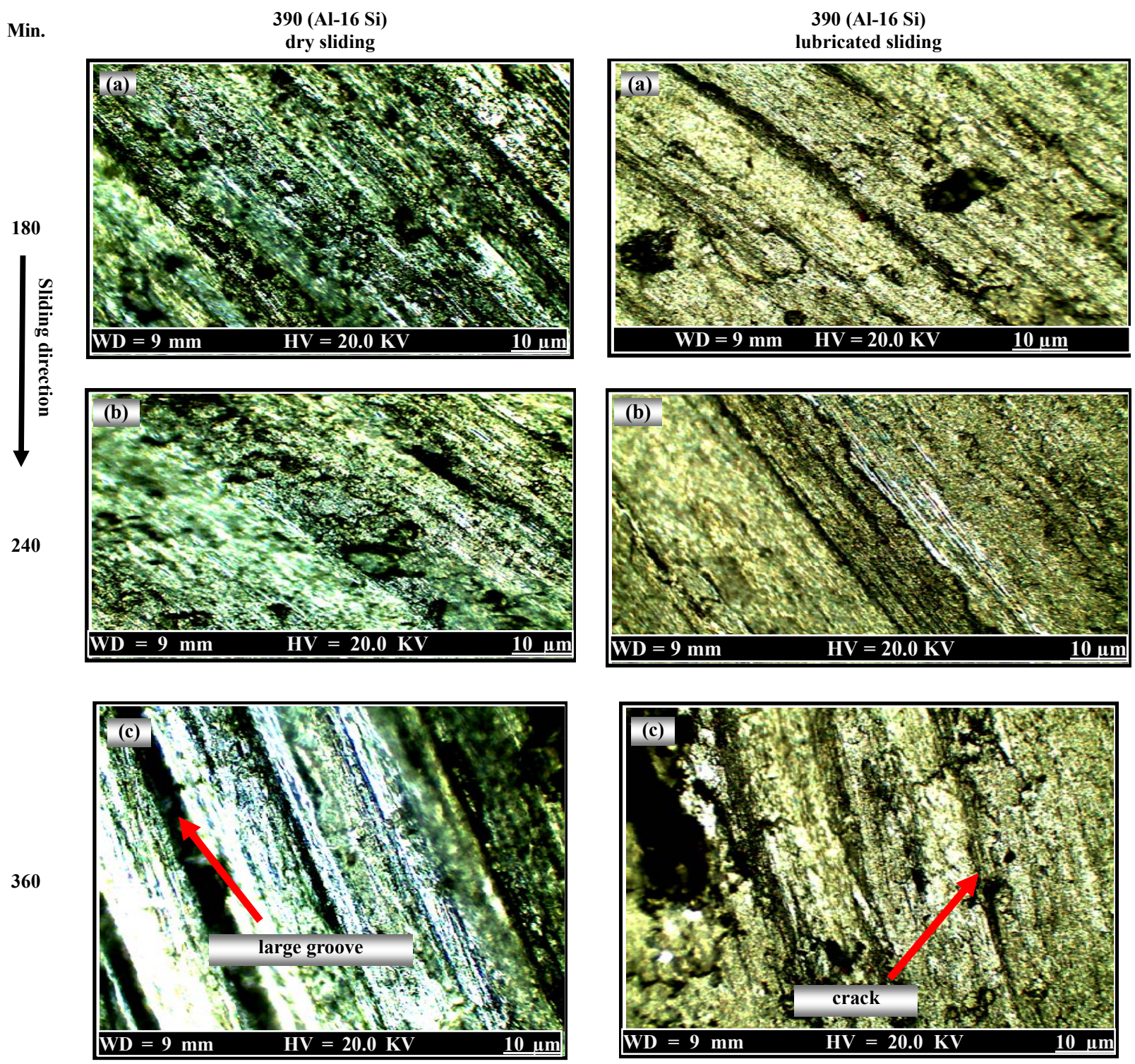

Figure 7. Surface comparisons under different loads (a) $10 \mathrm{~N}$; (b) $20 \mathrm{~N}$ and (c) $30 \mathrm{~N}$ at dry and lubricated sliding.
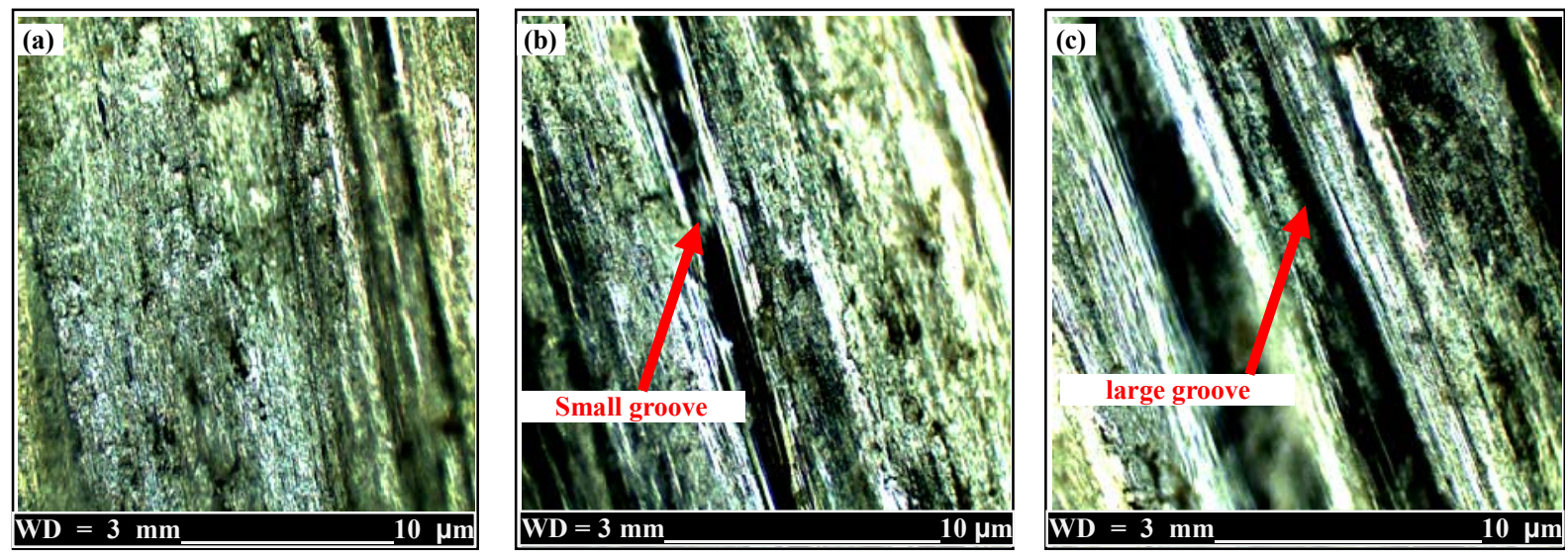

Figure 8. Micrographs after wear surface of $400 \mathrm{rpm}$ and load (a) $10 \mathrm{~N}$; (b) $20 \mathrm{~N}$; and (c) $30 \mathrm{~N}$ under dry conditions. 
- The higher value of friction is attributed to the higher value of $(R a)$. The smoothness of surface as well as sliding distance reduces the volumetric wear rate due to lacking wear resistance of material thin film;

- The friction increases as the surface roughness increases, it correlates inversely with load;

- The specific wear rate decreases as load increases, it correlates inversely with sliding velocity, which is attributed to thin film of material eroded between bumps of the disk surface.

Finally, it is predicted to apply this work for other alloys and future studies.

\section{Acknowledgements}

One of us (Y. A.) would like to acknowledge FRGS grants numbered: 9003-00249 \& 9003-00255 and TWASItaly, for full support of his visit to JUST-Jordan under TWAS-UNESCO Associateship.

\section{REFERENCES}

[1] M. A. De Buergo, C. Vazquez-Calvo and R. Fort, "The Measurement of Surface Roughness to Determine the Suitability," Geophysical Research Abstracts, Vol. 13, 2011, pp. 6443-6444.

[2] M. J. Caton, J. W. Jones, H. Mayer, S. Stanzl and J. E. Allison, "Demonstration of an Endurance Limit in 319 Aluminum," Chemistry and Materials Science, Vol. 34, No. 1, 2003, pp. 33-40.

[3] N. B. Nadu and T. V. Bi, "Effects of Surface Roughness on Porous Inclined Slider Bearings Lubricated with Micropolar Fluids," Journal of Marine Science and Technology, Vol. 15, No. 4, 2007, pp. 278-286.

[4] T. Mathia, F. Louis, G. Maeder and D. Mairey, "Relationships between Surfaces States, Finishing Processes and Engineering Properties," Wear, Vol. 83, No. 2, 1982, pp. 241-250. doi:10.1016/0043-1648(82)90180-6

[5] R. P. M. Procter, "Effect of Ion Implantation on Fatigue, Fretting and Fretting-Corrosion of Ti6Al-4V," Materials Science and Engineering, Vol. 115, 1989, pp. 307-314.

[6] A. J. Lee, "Cast Aluminum Alloy for High Tempruger Applications," In: S. K. Das, Ed., Automotive Alloys 2003, The Minerals, Metals \& Materials Society, NASA-Marshall, 2003.

[7] P. Chowdhury, S. Das and B. K. Datta, "Effect of Ni on the Wear Behavior of a Zinc Aluminum Alloy," Journal of Materials Science, Vol. 37, No. 10, 2002, pp. 21032107. doi:10.1023/A:1015297904125
[8] M. A. Chowdhury and M. M. Helali, "The Frictional Behavior of Mild Steel under Horizontal Vibration," Tribology International, Vol. 42, No. 6, 2009, pp. 946-950. doi:10.1016/j.triboint.2009.01.003

[9] M. L. Singla and V. I. Chawla, "Study of Wear Properties of Al-SiC Composites," Journal of Minerals \& Materials Characterization \& Engineering, Vol. 8, No. 10, 2009, pp. 813-819.

[10] P. L. Menezes and S. V. Kishore, "Influence of Roughness Parameters on Coefficient of Friction under Lubricated Conditions," Sadhana: Academy Proceedings in Engineering Sciences, Vol. 33, No. 3, 2008, pp. 181-190.

[11] K. J. Ku and T. G. Math, "Interface Roughness Effectfriction Map under Fretting Contact Conditions," Tribogy International, Vol. 43, No. 8, 2010, pp. 1500-1507. doi:10.1016/j.triboint.2010.02.010

[12] K. Kadirgama, M. Noor and M. M. Raman, "Surface Roughness Prediction Model 6061-T6 Aluminium Alloy Machining Using Statistical Method," European Journal of Scientific Research, Vol. 25, No. 2, 2009, pp. 250-256.

[13] Y. A. Karpenko and A. Akay, "Mechanical Engineering, a Numerical Model of Friction between Rough Surfaces," Tribology International, Vol. 34, No. 8, 2001, pp. 531545. doi:10.1016/S0301-679X(01)00044-5

[14] T. Rosalind and V. Wong, "Effects of Small-Scale Texturing on Ring Liner Friction in Largebore," ASME Internal Combustion Engine Division Fall Technical Conference, Sacramento, 5-8 November 2006.

[15] W. Wieleba, "The Statistical Correlation of the Coefficient of Friction and Wear Rate of PTFE Composites," Wear, Vol. 252, No. 9-10, 2002, pp. 719-729. doi:10.1016/S0043-1648(02)00029-7

[16] M. A. Chowdhury and M. Helali, "The Effect of Relative Humidity and Roughness on the Friction Coefficient under Horizontal Vibration," The Open Mechanical Engeering Journal, Vol. 2, 2008, pp. 128-135.

[17] P. Xing, B. Gao, Y. Zhuang, K. Liu and G. Tu, "On the Medication of Hypereutectic Al-Si Alloys Using Er," Acta Metallurgica Sinica (English Letters), Vol. 23, No. 5, 2010, pp. 327-333.

[18] M. Gupta and S. Ling, "Microstructure and Mechanical Properties of Hyp/Hypereutectic Al-Si Alloys Synthesized Using a Near-Net Shape Forming Technique," Journal of Alloys and Compounds, Vol. 287, No. 1-2, 1999, pp. 284294. doi:10.1016/S0925-8388(99)00062-6

[19] Y. Y. Li. D. Zhang, T. L. Ngat and W. Zhang, "RapidlySolidified Hypereutectic Al-Sialloys Prepared by Powder Extrusion," Transactions of Nonferrous Metals Society of China, Vol. 12, No. 5, 2002, pp. 878-881. 